Proceedings

\title{
Crystallization from the Gas Phase: Morphology Control, Co-Crystal and Salt Formation ${ }^{\dagger}$
}

\author{
Ciaran O'Malley ${ }^{1}$, Patrick McArdle ${ }^{1}$ and Andrea Erxleben 1,2,*
}

Citation: O'Malley, C.; McArdle, P.; Erxleben, A. Crystallization from the Gas Phase: Morphology Control,

Co-Crystal and Salt Formation.

Proceedings 2021, 78, 1. https://doi. org/10.3390/IECP2020-08797

Published: 1 December 2020

Publisher's Note: MDPI stays neutral with regard to jurisdictional claims in published maps and institutional affiliations.

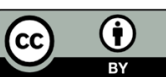

Copyright: (C) 2020 by the authors. Licensee MDPI, Basel, Switzerland. This article is an open access article distributed under the terms and conditions of the Creative Commons Attribution (CC BY) license (http://creativecommons.org/licenses/by/4.0/).
1 School of Chemistry, National University of Ireland Galway, H91TK33 Galway, Ireland; c.omalley16@nuigalway.ie (C.O.); patrick.mcardle@nuigalway.ie (P.M.)

2 Synthesis and Solid State Pharmaceutical Centre (SSPC), V94T9PX Limerick, Ireland

* Correspondence: andrea.erxleben@nuigalway.ie

+ Presented at the 1st International Electronic Conference on Pharmaceutics, 1-15 December 2020; Available online: https://iecp2020.sciforum.net/.

\begin{abstract}
Multicomponent crystallisation is a widely studied technique in pharmaceutical chemistry to enhance physical properties of API's such as solubility, stability and bioavailability without chemically modifying the drug moiety itself. Methods to produce multicomponent crystals are varied with solution crystallisation being the predominant method. Crystal morphologies also influence an API's properties with needle shaped crystals dissolving slower and possessing poor flow properties compared to a more equant block shape. In this paper, we discuss the preparation of cocrystals and co-crystal salts of two poorly soluble drugs, pyrimethamine and diflunisal. In particular, we compare production of multicomponent crystals via cosublimation with the more common methods of mechanical grinding and solution crystallisation. Samples are sublimed on a laboratory scale from both ends of standard $15 \times 160 \mathrm{~mm}$ test tubes sealed under vacuum with two heaters were used to equalize the sublimation rates of the components. We show that a range of multicomponent pharmaceutical crystals can be prepared that are not accessible via solution crystallisation, including polymorphs and ansolvates. In addition to binary systems, ternary crystals can also be obtained via this technique. Various diflunisal co-crystals crystallise as thin needles and we describe the use of tailor-made additives to obtain unprecedented morphology control of gas phase crystal growth. Finally, we discuss the formation of co-crystal salts in the absence of solvent. Salt formation was observed to occur during gas phase crystallisations in accordance with the pKa rule of 3 and modelling studies were carried out to understand the nature of proton transfer in these crystals in the absence of a solvent.
\end{abstract}

Keywords: co-crystallisation; sublimation; organic salt; proton transfer; morphology control

\section{Introduction}

Co-crystals, i.e., crystals containing two or more molecular components that crystallise together in the same crystal structure, are extensively studied in the field of pharmaceutical chemistry to enhance the physical properties of API's without chemical modification of the drug molecule itself [1-3]. Properties such as dissolution rate, solubility, processability, stability and bioavailability can be modified in such a manner. A related yet subtly different method of pharmaceutical preparation is API salt formation with a large number of API's marketed as salts with $\mathrm{HCl}$, sodium and sulfate salts among the most common [4]. A range of techniques are used in industry and on the laboratory scale for co-crystal production with solution crystallization being the most dominant method in tandem with other less common techniques such as solid state grinding, hot melt extrusion and spray drying [5]. Sublimation is a much less common technique for co-crystal formation with only a limited number of examples available in the literature but can provide a much greener alternative to crystal growth avoiding solvent needed for growth 
from solution which can also result in solvate formation [6-10]. In addition, crystals grown from solution can be of low quality for structural determination or result in solvate formation with solvent molecules present in a stoichiometric ratio in the crystal lattice [7]. Crystal morphology can have a significant effect on mechanical issues in industrial processes with more equant block shaped crystals much preferred to needle shaped crystals due to superior flow properties [11,12]. Crystal morphology can also have a significant impact on structural studies of a crystal system. However, the optimization of crystallisation processes to control morphology from solution has remained challenging [13].

Diflunisal, a non-seroidal anti-inflammatory drug (NSAID) and pyrimethamine, used for the treatment of toxoplasmosis and other parasitic diseases in AIDS/HIV patients, exhibit poor solubility in aqueous media while diflunisal has the additional problem of exhibiting extreme needle morphology both in the API itself and its co-crystals due to its preference for crystal growth by van der Waals stacking interactions [14-16]. Here we review and discuss our work aimed at enhancing the dissolution behaviour of both API's by co-crystallisation with selected co-formers while developing a new technique to synthesise and characterise these co-crystals. The successful use of tailor made additives and an apparatus constructed of inexpensive and commercially available components to obtain morphology control and improve the quality of crystal growth from the gas phase is also described.

\section{Experiments}

\subsection{Crystallisation from the Gas Phase and Crystal Structure Determination and Refinement}

Multicomponent crystals were crystallised from the gas phase as described previously by us [17]. An Oxford Diffraction Xcalibur system was used to collect X-ray diffraction data at room temperature. The crystal structures were solved using ShelxT and refined using Shelxl within the Oscail package [18-20].

\subsection{Ball Milling}

Equimolar amounts of the API and the respective coformers with $50 \mu \mathrm{L}$ of EtOH (120-150 mg total weight) were placed in $2 \mathrm{~mL}$ Eppendorf tubes containing one $5 \mathrm{~mm}$ stainless steel ball. The samples were placed in a 3D printed 6 tube sample holder developed in house and milled at $25 \mathrm{~Hz}$ for $20 \mathrm{~min}$ using an oscillatory ball mill (Mixer Mill MM400, Retsch GmbH \& Co., Haan, Germany).

\subsection{Solution Crystallisation}

Equimolar amounts of API and the respective co-former were dissolved in a minimum of solvent. Crystallisation experiments were carried out in methanol, acetonitrile and ethyl acetate. The solvent was allowed to slowly evaporate from an open $20 \mathrm{~mL}$ vial with X-ray suitable single crystals harvested in 7-14 days.

\section{Results}

\subsection{Pyrimethamine Co-Crystal Screening}

In an effort to synthesise three component crystals of pyrimethamine, a comprehensive study was carried out on the crystallization behaviour from ball milling, solution crystallization and co-sublimation [21]. Novel crystal systems identified from solution crystallization are outlined in Table 1 . It can be noted that many solvates were identified during this study and co-crystallisation from the gas phase was carried out to prevent solvate formation. Ansolvate structures identified from the gas phase are outlined in Table 2. 
Table 1. Novel Crystal Systems of Pyrimethamine Identified from Solution Crystallisation.

\begin{tabular}{|c|c|c|c|c|}
\hline No. & Components & Solvent Used & Solvate & Note \\
\hline 1 & $\begin{array}{l}\text { Pyrimethamine/Ben- } \\
\text { zoic acid }\end{array}$ & Methanol & Water & \\
\hline 2 & $\begin{array}{l}\text { Pyrimethamine/Ben- } \\
\text { zoic acid/Succinimide }\end{array}$ & Methanol & - & \\
\hline 3 & $\begin{array}{l}\text { Pyrimethamine/Nico- } \\
\text { tinic acid }\end{array}$ & Methanol & Water & \\
\hline 4 & $\begin{array}{c}\text { Pyrimethanime/Sac- } \\
\text { charin }\end{array}$ & Methanol & Water & $\mathrm{H}_{2} \mathrm{O}$ solvate I \\
\hline 5 & $\begin{array}{l}\text { Pyimethamine/Saccha- } \\
\text { rin }\end{array}$ & Methanol & Water & $\mathrm{H}_{2} \mathrm{O}$ solvate II \\
\hline 6 & $\begin{array}{c}\text { Pyrimethamine/Sac- } \\
\text { charin }\end{array}$ & Methanol & - & Polymorph II \\
\hline 7 & $\begin{array}{l}\text { Pyrimethamine/Sac- } \\
\text { charin }\end{array}$ & Methanol & Methanol & \\
\hline 8 & $\begin{array}{l}\text { Pyrimethamine/Sac- } \\
\text { charin }\end{array}$ & Acetonitrile & Acetonitrile & \\
\hline 9 & $\begin{array}{l}\text { Pyrimethamine/Sorbic } \\
\text { acid }\end{array}$ & Methanol & - & \\
\hline 10 & $\begin{array}{l}\text { Pyrimethamine/Sac- } \\
\text { charin/ Sorbic acid }\end{array}$ & Methanol & - & \\
\hline 11 & $\begin{array}{l}\text { Pyrimethamine/Man- } \\
\text { delic acid }\end{array}$ & Methanol & - & \\
\hline 12 & $\begin{array}{l}\text { Pyrimethamine/Sac- } \\
\text { charin/Glutarimide }\end{array}$ & Methanol & - & \\
\hline 13 & $\begin{array}{l}\text { Pyrimethamine/An- } \\
\text { thranillic acid }\end{array}$ & Acetonitrile & Water & \\
\hline 14 & Pyrimethamine & Acetonitrile & Acetonitrile & \\
\hline 15 & $\begin{array}{l}\text { Pyrimethamine/Ison- } \\
\text { icotinic acid }\end{array}$ & Acetonitrile & Water & \\
\hline
\end{tabular}

\subsection{Diflunisal Co-Crystal Screening}

Diflunisal was identified as an ideal candidate for crystallization from the gas phase due to its tendency to form highly anisotropic needle-like crystals and the formation of solvates from solution crystallization. Pallipurath et al. [15] previously did a comprehensive study of the crystallization behaviour of diflunisal with pyridyl derivatives and identified solvate formation as a particular hinderance to structure determination from the solution phase. Using co-sublimation, we have greatly improved the landscape of diflunisal co-crystals with the ability to determine structures that were previously unobtainable. Results are outlined in Table 2.

Table 2. Novel Multicomponent crystals synthesized using co-sublimation as described in [17].

\begin{tabular}{|c|c|c|c|c|c|}
\hline Components & $\begin{array}{l}\text { Amount } \\
\text { API (mg) }\end{array}$ & $\begin{array}{l}\text { Amount } \\
\text { Co-Former } \\
\text { (mg) }\end{array}$ & $\begin{array}{c}\text { Temperature } \\
\text { API }\left({ }^{\circ} \mathrm{C}\right)\end{array}$ & $\begin{array}{c}\text { Temperature } \\
\text { Co-Former } \\
\left({ }^{\circ} \mathrm{C}\right)\end{array}$ & Time (hr) \\
\hline DIF/INA & \multicolumn{2}{|c|}{$\begin{array}{c}50 \text { of milled sample (DIF } \\
250.2+\text { INA } 122.1+\text { BEN } \\
37.2)\end{array}$} & \multicolumn{2}{|c|}{$\begin{array}{l}\text { Heater } 1170.1 \\
\text { Heater } 2160.5\end{array}$} & 2 \\
\hline DIF/EBIPY & 25 & 9.1 & 180.0 & 140 & 2 \\
\hline DIF/BIPY & 50 & 15.6 & 193.0 & 126.3 & 2 \\
\hline
\end{tabular}




\begin{tabular}{cccccc}
\hline DIF/PBIPY & 50 & 39.62 & 174.4 & 50.0 & 12 \\
DIF/PIP & 50 & 17.2 & 196.4 & 61.8 & 12 \\
DIF/DMAP & 50 & 24.62 & 161.4 & 69.2 & 4 \\
\hline
\end{tabular}

\subsection{Morphology Control in the Gas Phase Using Tailor Made Additives}

It was reasoned that an additive of similar size and shape to one component of a cocrystal but possessing a lower $\mathrm{H}$ bonding capacity would introduce faults into stacked structures and therefore alter morphology of cocrystals where stacking interactions dominate crystal growth. Morphology control from the solution phase has been studied in detail with modest results, however using tailor made additives in the gas phase we were able to show much more drastic effects in morphology control.

\section{Discussion}

\subsection{Methods of Co-Crystallisation}

We looked at three main methods of crystallisation, each with their distinct advantages and disadvantages, Ball Milling, Solution Crystallisation and Sublimation. Mechanical grinding or ball milling is a common method of co-crystal screening. During milling mechanical energy is utilised and as it is a high energy process, milling of two or more co-formers together can induce a solid-state transition to bind the co-formers together as a co-crystal [22-24]. Sample preparation can take less than one hour with a usual quantitive yield if the co-formers used are suitable for co-crystallisation. Small catalytic amounts of solvent can be employed $(<20 \mu \mathrm{L})$ as a lubricant and to aid proton transfer in the sample. However, the main disadvantage by this method is the resulting powder sample where full structural characterisation by single crystal X-ray diffraction (SCXRD) is not possible. Therefore, it is often deployed as a screening process in tandem with solution crystallisation for full characterisation.

Solution crystallisation of co-crystals is the most common and go to method of producing single crystals [1] and indeed in many cases can produce high quality crystals suitable for SCXRD. However, its application is limited when the desired compound has solubility issues and oftentimes crystals produced from solution include solvent in the crystal lattice in a stoichiometric ratio as solvates [7]. Large volumes of various solvents can be required to screen samples and crystal formation can take several days to weeks. Therefore, we looked for a greener method of crystallisation that eliminates the disadvantages of solution crystallisation while providing access to structural characterisation that was previously unobtainable.

Around 2/3 of organic compounds are estimated to be sublimable and previously we have shown the application of sublimation to produce solvent free crystals and for polymorph selectivity for API's [6,7]. With the use of a small temperature gradient and under vacuum to prevent sample degradation high quality single crystals can be produced on a laboratory scale. This is achieved by slow growth rates during desublimation and clean condensing areas providing a low number of nucleation sites. We have now shown that high quality co-crystals can be produced also by sublimation by use of a two-zone oven to control the sublimation rates of the two components separately. The advantage of this method as a route to co-crystallisation is immediately obvious in that we completely avoid the need for solvent during crystallisation, eliminating the possibility of solvate formation. While the process is indeed limited to thermally stable and sublimable coformers, it has proved an extremely useful method for structure determination with the ability to grow high quality crystals in less than one day.

\subsection{Co-Crystallisation of Pyrimethamine}

A comprehensive co-crystal screening study of pyrimethamine was carried out with the aim of developing ternary crystal systems of pyrimethamine [21]. Pyrimethamine was identified from a crystal engineering view as having the ability to form ternary crystal 
systems due to the presence of a donor-acceptor-donor (DAD) and a donor-acceptor (DA) binding sites. During this study a number of novel crystal systems were identified by both solution and sublimation experiments, as outlined in Tables 1 and 2. While three novel ternary systems were identified from solution, namely pyrimethamine/saccharin/glutarimide, pyrimethamine/saccharin/sorbic acid and pyrimethamine/benzoic acid/succinimide along with a wide host of binary crystal systems and a novel pyrimethamine solvate with acetonitrile (Figure 1). It can be however noted the wide prevalence of solvate formation in binary crystals synthesised from solution, particularly prevalent in the pyrimethamine/saccharin system which gave one ansolvate, two hydrates, a methanol solvate and an acetonitrile solvate. To this end co-crystallisation experiments via sublimation were attempted in an attempt to crystallise the ansolvate structures which were identified as novel co-crystals via milling. We were successful in crystallising the ansolvate structure of nicotinic acid and a second ansolvate polymorph of pyrimethamine/saccharin. We were also able to crystallise two systems which were unobtainable via solution crystallisation; pyrimethamine/glutarimide and pyrimethamine/barbituric acid which were hindered by crystallisation from solution due to poor solubility in various solvents and resulting powder products. Most interesting from the sublimation of pyrimethamine was the ability to crystallise the ternary system pyrimethamine/saccharin/glutarimide from sublimation. This was due to the relatively similar sublimation rates at the same temperature of pyrimethamine and saccharin and showed that co-sublimation experiments can be expanded further to ternary or higher order systems by careful selection of coformers or modification of the heating oven to include more than two heating zones.

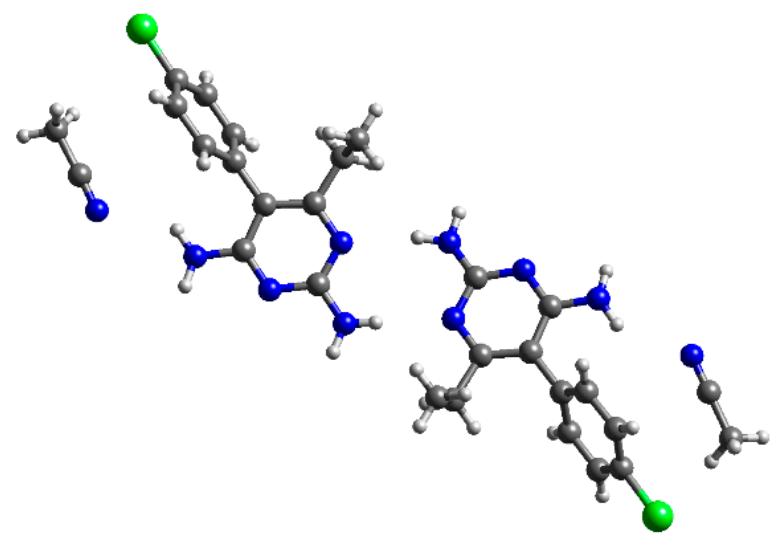

Figure 1. Pyrimethamine/Acetonitrile solvate identified from solution crystallisation.

\subsection{Co-Crystallisation of Diflunisal}

Diflunsal is a common non-steroidal anti-inflammatory drug (NSAID) which exhibits poor aqueous solubility and has a tendency to crystallise as long needles which are difficult to handle. In an attempt to modulate these properties a series of co-crystallisation screening was carried out by Pallipurath et al. [15] where diflunisal was co-crystallised with pyridyl containing moieties and while some crystal structures were found from solution crystallisation, more often than not the desired co-crystal failed to crystallise (e.g., diflunisal/bipyridine (BIPY)), formed a solvate (diflunisal/4-(2-pyridine-4-ethyl)pyridine (EBIPY)) or was unstable at room temperature when removed from solvent (diflunisal/4[3-(pyridin-4-yl)propyl]pyridine (PBIPY)). In an attempt to succeed where solution crystallisation had failed, a series of diflunisal co-crystals and salts were synthesised via cosublimation. We were able to synthesise a series of binary systems where solution crystallisation had failed as outlined in Table 3 including anhydrous DIF/BIPY, DIF/EBIPY and DIF/PBIPY. Of particular interest in these series of crystals was the example of diflunisal and isonicotinamide. A 2:1 co-crystal of this system has been extensively studied in the literature but due to "cotton candy" like crystallisation behaviour due to extreme van der 
Waals stacking, all efforts to achieve single crystal characterisation have failed. By co-sublimation and by use of benzamide as an additive in a $10 \%$ by weight ratio single crystals were able to be grown of sufficient quality for structure determination (Figure 2). The use of additives to control crystallisation morphology is discussed in the next section. This system showed a powerful example of the ability of co-sublimation to succeed in extreme cases where other crystallisation attempts have failed.

Table 3. Morphology control of co-crystals using additives.

\begin{tabular}{ccc}
\hline Components & Additive & Co-Crystal \\
\hline BZA/INA & - & $1: 1$ needles \\
BZA/INA & BEN & $1: 1$ blocks \\
BZA/INA & - & $2: 1$ plates \\
DIF/INA & - & $2: 1$ fibers \\
DIF/INA & BEN & $2: 1$ needles \\
DIF/BIPY & - & $2: 1$ needles \\
DIF/EBIPY & - & $2: 1$ thin plates \\
DIF/EBIPY & SPY & $2: 1$ needles \\
\hline
\end{tabular}
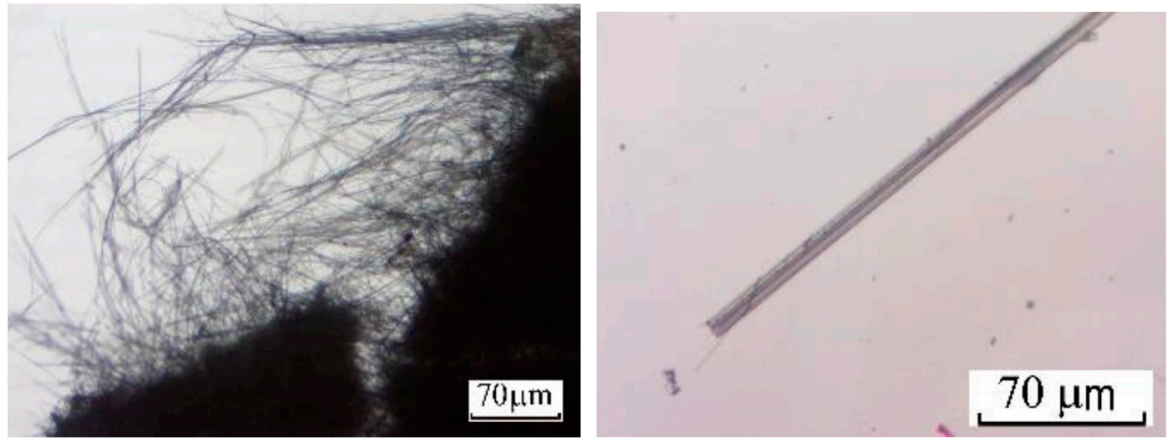

Figure 2. DIF/INA crystallised from the gas phase without (top) and with the presence of benzamide (bottom). Reproduced from [17] with permission from the Royal Society of Chemistry.

\subsection{Morphology Control in the Gas Phase}

Morphology control is of particular interest to the pharmaceutical industry, the size and shape of a crystal dramatically affect a solid's manual handling ability [11-13]. More equant block shaped crystals are much preferred in industry over more anisotropic plate or needle shapes due to their flow properties with blocks acting much like spheres whereas needles and plates can accumulate and cause blockages in industrial equipment. On a laboratory scale, block shaped crystals are much preferred over plates due to their diffraction properties with needle shaped crystals in general taking longer to collect weaker data for than block shaped crystals. As such, we endeavoured to influence the morphology of crystals during growth to a more desired shape. It was reasoned that an additive of similar size and shape to one component of a cocrystal (tailor made additives) but possessing a lower $\mathrm{H}$ bonding capacity would introduce faults into stacked structures and therefore alter morphology of cocrystals where stacking interactions dominate crystal growth.

To start the BZA/INA crystal system was examined. 1:1 and 2:1 crystal systems are known to exist [10,25-27] for these cofomers with only the $1: 1$ system characterised by SCXRD. Previous crystals reported for the 2:1 system were poorly diffracting or twinned with no structural data available. We succeeded in growing 1:1 and 2:1 crystals via cosublimation. 1:1 crystals grown by sublimation were observed as needles with a sea urchin habit but with the introduction of $1 \%$ benzoic acid, similar to isonicotinamide but lacking a hydrogen bonding pyridyl nitrogen, the crystals demonstrated a dramatic change to a 
block like morphology. This is in stark contrast to morphology changes previously observed from solution which prove much more modest in scale.

Likewise, we studied the morphology behaviour of the DIF/EBIPY system. The 2:1 crystal grown from sublimation gave very thin plates which proved difficult to collect structural data for as the fine plates were very weakly diffracting. The addition of 5\% 4styrylpyridine (SPY) the plates were able to be converted to needles which gave much stronger diffraction than the thin plates (Figure 3). We can use the DIF/EBIPY system to explain how tailor made additives have such a dramatic effect on morphology from gas phase crystal growth. In the plates the predominant growth direction is along the c-axis with extended growth along the a-axis and negligible growth along the b-axis. Along the c-axis EBIPY is orientated in the lattice to provide hydrogen bond driven growth sites (Figure 4). Poisoning of these sites with SPY allows the SPY to hydrogen bond to diflunisal but providing no extra hydrogen bonding site for additional growth, preventing further growth in this direction. With the c-axis being controlled the predominant growth face then becomes the a-axis which is the molecular stacking direction.
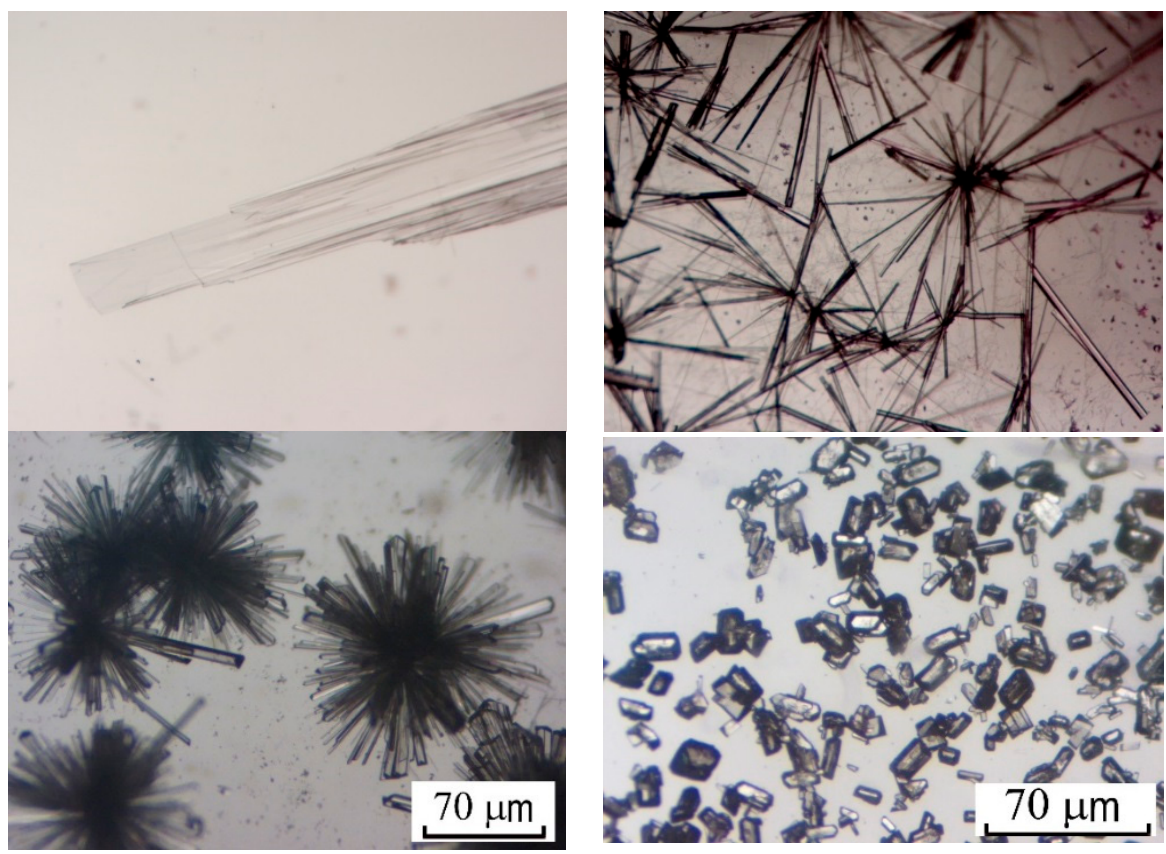

Figure 3. (top) DIF/EBIPY crystallised without additive (left) and with SPY (right). (bottom) BZA/INA 1:1 crystallised without additive (left) and with BEN (right). 


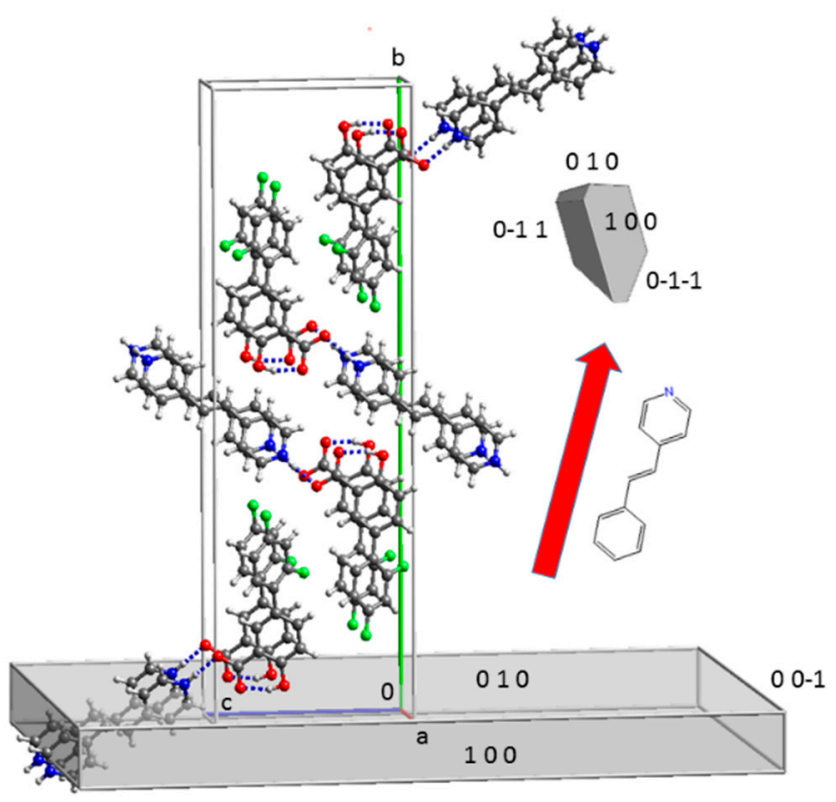

Figure 4. DIF/EBipy crystal structure with growth as plate and needle shaped crystals. Reproduced from [17] with permission from The Royal Society of Chemistry.

\subsection{Modelling Hydrogen Transfer in the Gas Phase}

It is widely established that salt formation will occur when the pKa difference between two coformers is greater than 3 [26]. This rule was however developed using crystals grown from the solution phase and from crystals outlined in Table 4, it is shown that this rule holds also for multicomponent crystals grown from the gas phase. However, while it is clear that salt formation has occurred in the crystals grown from sublimation, the question then becomes when exactly does proton transfer take place? It is possible that proton transfer can take place before sublimation with the gas phase species being ionic $[27,28]$ or that proton transfer occurs after desublimation during early stage crystal growth. It is known ions are extremely difficult to generate in the gas phase [29], suggesting proton transfer elsewhere. We have studied proton transfer in gas phase crystallisation by computational methods utilizing molecular clusters which will be published elsewhere.

Table 4. pKa differences of diflunisal and co-formers.

\begin{tabular}{cccc}
\hline Compound & pKa & Difference (Base-DIF) & Outcome \\
\hline Diflunisal & 2.94 & 0 & - \\
BIPY & 3.39 & 0.33 & Co-crystal \\
INA & 3.39 & 0.45 & Co-crystal \\
EBipy & 5.5 & 2.56 & Co-crystal \\
PBipy & 6.3 & 3.36 & Salt \\
DMAP & 9.7 & 6.76 & Salt \\
Piperazine & 9.83 & 6.89 & Salt \\
\hline
\end{tabular}

\section{Conclusions}

We have shown that pharmaceutical co-crystals can be grown by sublimation by equalising the sublimation rates of the components by multiple zone heating with crystal quality controlled by suppressing nucleation with close control over growth rates and desublimation surfaces. Tailor made additives can be used both to control morphology in co-crystal systems and to improve crystal quality for X-ray characterisation. Ternary crystals have been shown to form via sublimation, opening the possibilities for higher order 
crystal systems via this method. We have shown that sublimation can be an important complementary technique to ball milling and solution crystallization for the investigation and characterisation of pharmaceutical solids.

\section{Institutional Review Board Statement: Not applicable.}

Informed Consent Statement: Not applicable.

Data Availability Statement: The data presented in this study are available in this article and in the cited literature.

Acknowledgments: This publication has emanated from research supported in part by a research grant from Science Foundation Ireland (SFI) and is co-funded under the European Regional Development Fund under Grant Number 12/RC/2275.

Conflicts of Interest: The authors declare no conflict of interest.

\section{References}

1. Aitipamula, S.; Banerjee, R.; Bansal, A.K.; Biradha, K.; Cheney, M.L.; Choudhury, A.R.; Desiraju, G.R.; Dikundwar, A.G.; Dubey, R.; Duggirala, N.; et al. Polymorphs, salts, and cocrystals: What's in a name? Cryst. Growth Des. 2012, 12, $2147-2152$.

2. Bolla, G.; Nangia, A. Pharmaceutical cocrystals: Walking the talk. Chem. Commun. 2016, 52, 8342-8360.

3. Schultheiss, N.N.; Pharmaceutical, A. Cocrystals and their physicochemical properties. Cryst. Growth Des. 2009, 9, $2950-2967$.

4. Wiedmann, T.S.; Naqwi, A. Pharmaceutical salts: Theory, use in solid dosage forms and in situ preparation in an aerosol. Asian J. Pharm. Sci. 2016, 11, 722-734.

5. Karimi-Jafari, M.; Padrela, L.; Walker, G.M.; Croker, D.M. Creating cocrystals: a review of pharmaceutical cocrystal preparation routes and applications. Cryst. Growth Des. 2018, 18, 6370-6387.

6. Kamali, N.; O'Malley, C.; Mahon, M.F.; Erxleben, A.; McArdle, P. Use of sublimation catalysis and polycrystalline powder templates for polymorph control of gas phase crystallization. Cryst. Growth Des. 2018, 18, 3510-3516.

7. Karpinska, J.; Erxleben, A.; McArdle, P. Applications of low temperature gradient sublimation in vacuo: Rapid production of high quality crystals. The first solvent-free crystals of ethinyl estradiol. Cryst. Growth Des. 2013, 13, 1122-1130.

8. Perlovich, G.L.; Ryzhakov, A.M.; Tkachev, V.V.; Hansen, L.K.; Raevsky, O.A. Sulfonamide molecular crystals: Structure, sublimation thermodynamic characteristics, molecular packing, hydrogen bonds networks. Cryst. Growth Des. 2013, 13, 4002-4016.

9. Eddleston, M.D.; Sivachelvam, S.; Jones, W. Screening for polymorphs of cocrystals: a case study. CrystEngComm 2013, 15, 175181.

10. Carstens, T.; Haynes, D.A.; Smith, V. Cocrystals: Solution, Mechanochemistry and Sublimation. Cryst. Growth Des. 2020, 20, 1139-1149.

11. Chen, J.; Trout, B.L. Computer-aided solvent selection for improving the morphology of needle-like crystals: A case study of 2,6-dihydroxybenzoic acid. Cryst. Growth Des. 2010, 10, 4379-4388.

12. MacLeod, C.S.; Muller, F.L. On the fracture of pharmaceutical needle-shaped crystals during pressure filtration: Case studies and mechanistic understanding. Org. Process. Res. Dev. 2012, 16, 425-434.

13. Huang, Y.; Wang, Z.; Chen, Z.; Zhang, Q. Angew. Chem Int. Ed. 2019, 58, 9696-9711.

14. Evora, A.O.L.; Castro, R.A.E.; Maria, T.M.R.; Silva, M.R.; ter Horst, J.H.; Canotilho, J.; Eusebio, M.E.S. A thermodynamic based approach on the investigation of a diflunisal pharmaceutical co-crystal with improved intrinsic dissolution rate. Int. J. Pharm. 2014, 466, 68-75.

15. Pallipurath, A.R.; Civati, F.; Eziashi, M.; Omar, E.; McArdle, P.; Erxleben, A. Tailoring Cocrystal and Salt Formation and Controlling the Crystal Habit of Diflunisal. Cryst. Growth Des. 2016, 16, 6468-6478.

16. Stanley, N.; Sethuraman, V.; Muthiah, P.T.; Luger, P.; Weber, M.; Crystal, M. Engineering of organic salts: Hydrogen-bonded supramolecular motifs in pyrimethamine hydrogen glutarate and pyrimethamine formate. Cryst. Growth Des. 2002, 2, 631-635.

17. O'Malley, C.; Erxleben, A.; Kellehan, S.; Mcardle, P. Unprecedented morphology control of gas phase cocrystal growth using multi zone heating and tailor made additives. Chem. Commun. 2020, 56, 5657-5660.

18. McArdle, P. Oscail, a program package for small-molecule single-crystal crystallography with crystal morphology prediction and molecular modelling. J. Appl. Crystallogr. 2017, 50, 320-326.

19. Sheldrick, G. SHELXT-Integrated space-group and crystal-structure determination. Acta Crystallogr. Sect. A: Found. Adv. 2015, 71, 3-8.

20. Sheldrick, G. Crystal structure refinement with SHELXL. Acta Crystallogr. Sect. C: Cryst. Struct. Commun. 2015, 71, 3-8.

21. O'Malley, C.; Erxleben, A.; McArdle, P.; Simmie, J.M. Crystallization of organic salts from the gas phase: When does proton transfer take place? Cryst. Growth Des. 2021, 21, 23-27.

22. Macfhionnghaile, P.; Hu, Y.; Gniado, K.; Curran, S.; Mcardle, P.; Erxleben, A. Effects of Ball-Milling and Cryomilling on Sulfamerazine Polymorphs: A Quantitative Study. J. Pharm. Sci. 2014, 103, 1766-1778.

23. Chow, P.S.; Lau, G.; Ng, W.K.; Vangala, V.R. Stability of pharmaceutical cocrystal during milling: A case study of 1:1 caffeine-glutaric acid. Cryst. Growth Des. 2017, 17, 4064-4071. 
24. Kaur, N.; Duggirala, N.K.; Thakral, S.; Suryanarayanan, R. Role of lattice disorder in water-mediated dissociation of pharmaceutical cocrystal systems. Mol. Pharm. 2019, 16, 3167-3177.

25. Aakeröy, C.B.; Beatty, A.M.; Helfrich, B.A. Angew. Chem. Int. Ed. 2001, 40, 3240-3242.

26. Maher, A.; Rasmuson, Å; Croker, D.M.; Hodnett, B.K. Solubility of the Metastable Polymorph of Piracetam (Form II) in a Range of Solvents. J. Chem. Eng. Data 2012, 57, 3525-3531.

27. Burk, P.; Koppel, I.; Trummal, A.; Koppel, I.A. Feasibility of the spontaneous gas-phase proton transfer equilibria between neutral Brønsted acids and Brønsted bases. J. Phys. Org. Chem. 2008, 21, 571-574.

28. Earle, M.J.; Esperança, J.M.; Gilea, M.A.; Canongia, J.N.; Lopes, L.; Rebelo, P.N.; Magee, J.W.; Seddon, K.R.; Widegren, J.A. The distillation and volatility of ionic liquids. Nature 2006, 439, 831-834.

29. Raczyńska, E.; Decouzon, M.; Gal, J.F.; Maria, P.C.; Gelbard, G.; Vielfaure-Joly, F. Gas-phase structural (internal) effects in strong organic nitrogen bases. J. Phys. Org. Chem. 2001, 14, 25-34. 